\title{
Knowledge Management Implementation in a Government Research Institute in Selangor, Malaysia
}

\author{
Nazatul Aisha Md Ramin ${ }^{1}$, Khairul Mizan Taib ${ }^{1}$, Dang Merduwati Hashim ${ }^{1}$, \\ Siti Arpah Noordin ${ }^{1}$ and Siti Munira Yasin ${ }^{2}$ \\ ${ }^{1}$ Faculty of Information Management, Universiti Teknologi MARA, Puncak Perdana Campus, Shah \\ Alam, Selangor, Malaysia \\ ${ }^{2}$ Population Health and Preventive Medicine, Faculty of Medicine, Universiti Teknologi MARA, Sungai \\ Buloh, Selangor, Malaysia
}

Correspondence should be addressed to: Nazatul Aisha Md Ramin; nazatulaisha@yahoo.com

Received 12 January 2013; Accepted 10 June 2013; Published 30 October 2013

Copyright (C) 2013 Nazatul Aisha Md Ramin, Khairul Mizan Taib, Dang Merduwati Hashim, Siti Arpah Noordin and Siti Munira Yasin. Distributed under Creative Commons CC-BY 3.0

\begin{abstract}
Knowledge is recognised as an important asset in any organisations these days. Unfortunately, many organisations are not doing enough to effectively manage this important asset in creating and maintaining their competitive advantage. The objective of this study was to investigate the implementation of knowledge management in a government research institute in Selangor, Malaysia. This explorative study employs both quantitative and qualitative approaches to achieve the research objectives. A set of questionnaires was developed using online survey software. This set was sent to 96 respondents from five divisions based on a simple random sampling method. The questionnaires comprised items that were used to investigate the understanding and awareness of KM in the chosen organisation. The data were analysed using the Lime Survey statistic, Chi Squared tests and Reliability analysis. For the qualitative component, the interview method was used. This method was conducted to determine the KM process implementation in the organisation and focuses on the Knowledge Management Section (KMS). The interview data were analysed using ATLAS.ti software. The results showed that three main factors affected knowledge management implementation in the company; namely, organisation, people and technology. We suggest that a need exists within any organisation to strengthen the implementation process to successfully obtain the benefits of knowledge management in creating and sustaining competitive advantage.
\end{abstract}

Keywords: Knowledge management implementation, research institute, awareness, problems and obstacles.

\section{Introduction}

Knowledge, recognised as being an important resource to organisations these days, has to be effectively and efficiently managed for organisations to leverage on it to obtain competitive advantage to achieve success in the dynamic business environment. Thus, in today's world knowledge management plays a vital role in contributing to the success of profit and non-profit organisations. As mentioned by

Cite this Article as: Nazatul Aisha Md Ramin, Khairul Mizan Taib, Dang Merduwati Hashim, Siti Arpah Noordin and Siti Munira Yasin (2013), "Knowledge Management Implementation in a Government Research Institute in Selangor, Malaysia," Communications of the IBIMA, Vol. 2013 (2013), Article ID 476066, DOI: 10.5171/2013.476066 
Karadsheh et al. (2009), knowledge has become a key resource for organisations to improve their business performance. In addition, Sanchez et al. (2000) asserted that knowledge is considered to be the main intangible ingredient in a melting pot that makes innovation possible in an organisation. Therefore, most organisations choose to include knowledge management in their management function.

\section{Knowledge Management Implementation}

It has been stated that knowledge management is a management discipline that focuses on the development and use of knowledge to support and achieve the business objective of organisations (Salleh et al., 2003). Knowledge management is a planned, structured approach to manage the creation, sharing, harvesting and leveraging of knowledge as an organisational asset, to enhance a company's ability, speed and effectiveness in delivering products or services for the benefit of clients, in line with its business strategy. Knowledge management takes place on three levels-the individual level, team level and organisational level. It is a holistic solution incorporating a variety of perspectives-people, process, culture and technology perspectives, all of which carry equal weighting (Plessis and Boon, 2004). In other words, knowledge management is an approach that many commercial companies adopt to enhance their business function and operation.

The implementation of knowledge management in an organisation allows improvement of the speed of information and knowledge timeliness, product and service dynamics and the increased globalisation of output (Greiner et al., 2007). Earlier studies have stated that the process of knowledge management implementation is influenced by human resources, information technology and knowledge management practice. Furthermore, for an organisation to be creative and innovative in the global marketplace, it should focus on the technology, people and practices required for its implementation (Chong, 2006).
There are many general barriers to successful implementation of knowledge management. These barriers include viewpoints of the meaning of knowledge management and its implementation in a company, organisational culture, shared understanding of knowledge management and limited buy-in from top management or supporting staff (Plessis and Boon, 2004, Lang, 2001). Furthermore, Low retention rates of staff due to new opportunities arising in the market, create a high attrition rate in the job market in most first world countries (Lindsey, 2006). Other factors include cost of implementation (McCann and Buckner, 2004), role of technology, role of staff skill levels, organisation management style, user acceptance (Lucas, 2006, McDermott and O'Dell, 2001, Rezgui, 2007) and role of understanding critical knowledge to keep (McCann and Buckner, 2004). Understanding what these barriers are important to identify areas of weakness that a knowledge management programme may have upfront. In this way, organisations can cater for these weaknesses and try to build mechanisms to overcome them before implementation.

Today, most organisations realise that they need to become knowledge-based organisations to operate successfully and effectively. Nevertheless, few organisations understand the meaning of knowledge management and how to proceed with implementing knowledge management within their organisation.

\section{The Development of Knowledge Management in Malaysia}

The knowledge management agenda was inspired by the fourth Malaysian Prime Minister, Tun Dr. Mahathir Mohammad, in 1991. His brilliant idea emphasised the need to transform the nation's economy towards a knowledge-based economy in tandem with Vision 2020. Malaysia is envisaged to acquire developed nation status by 2020. Despite these enthusiastic ideas, the concept and practices of knowledge management started gradually and began to take off only in the late 1990s (Salleh et al., 2003). Knowledge 
management evolved in Malaysia when a few multinational companies, namely Microsoft and Hewlett-Packard (HP), introduced their existing knowledge management practices, processes and applications. The new national interest in this area embarked simultaneously (Salleh et al., 2003).

Through the 'Knowledge Economy Master Plan', Malaysian government agencies and companies were inspired to adopt KM (Syed-Ikhsan and Rowland, 2004). One of the earliest government-linked companies (GLCs) that has practiced KM in the early 1990s was the Multimedia Development Corporation (MDC).

Since the early 1990s, Malaysia began paving the path and laying the foundation for its knowledge-based economy (keconomy) bearing the notion that continual effort is needed to improve the nation's and it's industries' competitive position (Mohammed, 2007, Jayasingam et al., 2012). However, the initiatives only began to gain notable momentum in the late 1990s and early 2000 with the establishment of the Multimedia Super Corridor and its flagships (1996), the Third Outline Prospective Plan (2001), and the Knowledge Economy Master Plan.

Knowledge Management (KM) initiatives were also set up at various government organizations (e.g. INTAN, MAMPU, MINT, SIRIM, Telekom Malaysia, TNB), educational institutions (e.g. Multimedia University, Universiti Putra Malaysia (UPM), Open University Malaysia (OUM), Monash University (Malaysia), Universiti Teknologi Mara (UITM)), and even financial institutions (e.g. CIMB, OCBC, Bank Mualamat) (Chowdhury, 2006). The measures undertaken by such institutions as mentioned above focuses on the development of knowledge enablers such as the development of human capital, research and development, information and communication technology, infrastructure and info-structure, and so on.

Evidently, concerted effort is in place to help the transformations of organizations to become knowledge-intensive firms. However, even with all these combined efforts by the Government, the impact and actual results of these initiatives are yet to be seen. In spite of the increasing attention showered upon KM, organizations have yet to achieve the desired level of KM especially in terms of knowledge creation.

Given the situation, one might think there must be some progress, especially in terms of knowledge creation. Conversely, a survey conducted by (Mohammed, 2007) on 1819 organizations from 18 industries found that despite the numerous initiatives in place, Malaysia was reported to be still lagging behind leading economies such as the United States and Singapore with regards to knowledge enablers specifically in terms of educated population, the number of computers, and the number of internet users.

Malaysia was reported to be almost at par with developed nations only in terms of technological cooperation. Other attempts to evaluate $\mathrm{KM}$, led researchers to report that the implementation of KM was still relatively slow in Malaysian (Rahman, 2004, Hoon et al., 2003, Chong, 2006). Although most organizations were aware of KM and its impending benefits, they found that the level of implementation was not at par with the level of awareness (Chong et al., 2006).

Furthermore, it has been reported that there is a wide discrepancy in the level of KM practices in Malaysia when compared to leading economies and foreign owned firms (Mohammed, 2007). Although the second phase of the Knowledge Content Survey reported that the extent of knowledge enablers such as human capabilities, knowledge leadership, technology/info structures, and knowledge environment has improved across industries since the first survey, a decline was noted in the level of knowledge processes (knowledge generation, acquisition, sharing, and utilization) (Jayasingam et al., 2012). In fact, most Malaysian firms leaned towards knowledge acquisition through hiring and shied away 
from actual knowledge acquisition (Jayasingam et al., 2012).

This study aims to identify the extent of the implementation and practice of KM in the chosen company, i.e., Organisation X. The results of the present study should be able to provide the company with some information regarding their knowledge management practices. In addition, this study will also highlight some useful recommendations on how to improve knowledge management practices within their organisation. Next, the results are expected to increase the level of knowledge regarding KM practices. Finally, our study may also provide important information regarding $\mathrm{KM}$ practices and implementation within any organisation that acts in a very similar manner.

\section{The Development of KM in Organisation X}

KM initiatives took place in Organisation $\mathrm{X}$ in 2008, managed by the IPKM (Intellectual Property \& Knowledge Management) Department, a section that provides knowledge to staff and public users. IPKM also acts as a library to Organisation X.

In 2010, KM was managed by KM and Asset Management because Organisation X had treated knowledge management as an asset towards their business functions. Knowledge management was perceived to enhance Organisation X's business performance, productivity, staff hiring, research and development, etc.

In relation to the newly adopted approach, Organisation X developed several strategies such as Seminars on KM, Note Booklet, knowledge databank and policies that ensured the success of knowledge management implementations in Organisation $\mathrm{X}$. Other $\mathrm{KM}$ initiatives undertaken by Organisation X include a KM Awareness Program, a KM Breakthrough Team and a KM portal (for example, Myinfo).

In Malaysia, Organisation $\mathrm{X}$ is well known for its experience and expertise in research and technology development, acting as the government's mandated apparatus. Organisation $\mathrm{X}$ is wholly owned by the Malaysian Government under the Minister of Finance Incorporated. Organisation $\mathrm{X}$ is also recognised as a global research and standard development organisation. Because the importance of knowledge management is crucial to business operations, Organisation $\mathrm{X}$ has developed and implemented knowledge management. Accordingly, Organisation X has developed a Knowledge Management Section (KMS), which is responsible for organising all KM activities.

The unmanageability of knowledge assets illustrates that most organisations fail to recognise the importance of knowledge management. Lack of knowledge management awareness and poor knowledge management practices might lead to a loss of corporate memory. Furthermore, lack of knowledge sharing among staff may create a knowledge gap within organisations. Many organisations also do not realise that cooperation from all levels of staff is required for successful knowledge management implementation.

Another issue regarding the implementation of knowledge management is that many staff members are not familiar with the concept of knowledge management. This shows that the level of understanding by staff regarding knowledge management remains at infancy. Poor understanding of the concept behind knowledge management and its benefits may be due to lack of implementation of knowledge management in organisations. Therefore, there is a need to explore the awareness of knowledge management and its practices in a local organisation in Malaysia. This study also investigates the extent to which the knowledge management that has been implemented in the organisation has been successful.

To fulfil the purpose of this study, appropriate data are required to answer the following questions: 
1. What are the levels of understanding of KM among the staff in Organisation X?

2. Are staff members aware of the importance of knowledge management?

3. What are the benefits of implementing knowledge management in Organisation X?

4. What are the problems and obstacles faced in implementing KM?

\section{Research Methodology}

This study focuses on middle management and top management, including their business processes, activities and policies regarding knowledge management. The questionnaire was distributed to the President's Office, the Marketing and Business Development Division, the Design and Engineering Division, the Research and Technology Development Division, the Standards and Quality Division, the Corporate Division, and Subsidiaries. Two KMS staff members were chosen for the interview sessions: the Head of KMS and an officer who is responsible for knowledge management activities.

This study employs both quantitative and qualitative approaches to answering the research objectives. These approaches include an online survey using the Lime Survey application. The aim was to determine the level of understanding and awareness of knowledge management among the staff within Organisation X. In- depth interviews were conducted at the Knowledge Management Section (KMS) in Organisation $\mathrm{X}$ with the two most pertinent people regarding knowledge management implementation. These individuals were selected based on their experience and involvement in the KM initiatives.

\section{Statistical Analysis}

For the quantitative approach, the data were analysed using SPSS 16.0 for Windows, which includes Chi squared tests and Reliability analysis. The data were analysed and divided into three independent variables: age, gender and division. Reliability results indicated a good reliability results for all KM measures (application, benefit, access, problem and effectiveness), ranging between 0.73- 0.94. The fact that the alpha values are greater than 0.70 indicates that the data collected are reliable.

For the qualitative interviews, the data were analysed using ATLAS.ti.

\section{Results}

The findings of the study are as follows:

\section{Qualitative Analysis}

Based on the data analysis, Organisation X has implemented knowledge management in their business functions. Three factors influence the implementation of knowledge management in Organisation X; namely, Organisation, People and Technology.

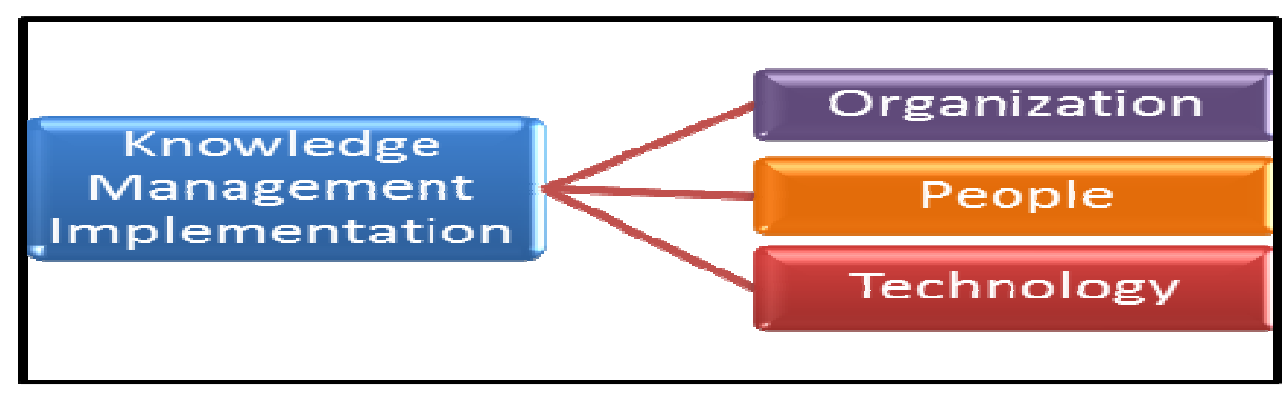

Figure 1: The Key Factors of the Implementation of Knowledge Management 


\section{Organisation}

Organisation is one of the factors that have a wide influence on the success of knowledge management implementation. Marshall and Prusak (1996) asserted many organisations are highly successful due their having well-designed knowledge management strategies. The attention given to the implementation of knowledge management in Organisation $X$ has increased significantly because knowledge management has affected the organisation's performance.

In Organisation X, knowledge management is practiced in several departments such as the Library (the first to implement KM place), the KM Section, KM representatives (representatives from each division), KM steering committees and the KM manager (Head of KMS). It can be concluded that Organisation $\mathrm{X}$ has paid serious attention to knowledge management practices, thereby ensuring its success.

\section{People}

During the interview sessions, it was identified that people-based factors such as awareness, level of understanding and knowledge sharing are important components that lead to the successful implementation of knowledge management.

\section{Technology}

Technology is the most essential enabling tool that provides support for knowledge management in organisations. Without good technology, the implementation of knowledge management will not be effective. Because technology plays a vital role in the implementation of knowledge management, Organisation $\mathrm{X}$ has facilitated technology advances that are used to develop knowledge management practices.

Organisation X has developed a KM Centre Portal known as I-PORT, which includes the following functions: document upload, blogging, a forum, e-learning, tips, a newspaper, publications, etc. Management uses the KM system to facilitate their daily work. Therefore, there is a need for the technology because it provides effective support for the implementation of knowledge management in Organisation X. As a result, Organisation $X$ has demonstrated that technology significantly supports the effectiveness of and efficiencies created by the implementation of knowledge management.

\section{Quantitative Results}

This study involved 129 respondents. In the study, 96 respondents returned completed questionnaires, and the remaining 33 respondents returned incomplete questionnaires. Twenty four out of 96 respondents were from the Standard and Quality Division. Forty percents of respondents were female. Age group ranged from 22-60 years old, with the majority within the 25-35 age group (30\%).

Table 1. Awareness of KM

\begin{tabular}{|l|c|c|}
\hline \multicolumn{2}{|c|}{ Frequency } & Percent (\%) \\
\hline Never heard of it & 2 & $2.08 \%$ \\
\hline At professional and academic conferences & 17 & $17.71 \%$ \\
\hline Reading about KM in literature & 38 & $39.58 \%$ \\
\hline Attended a workshop on it & 19 & $19.79 \%$ \\
\hline Learn from colleagues & 33 & $34.38 \%$ \\
\hline Learn from practical work & 25 & $26.04 \%$ \\
\hline Other & 12 & $12.50 \%$ \\
\hline Total & 96 & $100.0 \%$ \\
\hline
\end{tabular}


Table 1 specifies the knowledge of staff regarding KM practices. Results show that there are a number of respondent that clarify that had never heard of KM. Some identify it through several of media such as newspaper, TV, radio and etc. Thus, it can conclude that the staffs in the organization majority had some awareness of KM which were obtained informally various sources such as electronic media, web, literature, seminar and meetings.

Table 2: Perception of Knowledge that is Critical to Operational Activity of Company X

\begin{tabular}{|l|c|c|}
\hline & Frequency & Percent (\%) \\
\hline Technical report & 70 & $72.92 \%$ \\
\hline Research papers & 64 & $66.67 \%$ \\
\hline Books & 55 & $57.29 \%$ \\
\hline Online database & 61 & $63.54 \%$ \\
\hline Standards & 62 & $64.58 \%$ \\
\hline Refereed journal & 54 & $56.25 \%$ \\
\hline Proceedings & 38 & $39.58 \%$ \\
\hline Presentation & 53 & $55.21 \%$ \\
\hline Seminars Papers & 45 & $46.88 \%$ \\
\hline Market report & 8 & $8.33 \%$ \\
\hline
\end{tabular}

Table 2 displays the perceived importance of KM in operational activities. Technical report was shown to be ranked highest to their operation as a research organization. Participants also identified statistical report, guideline and procedures, direct interactions, newsletter, flow chart, thesis and engineering design as essential for their operational activity.

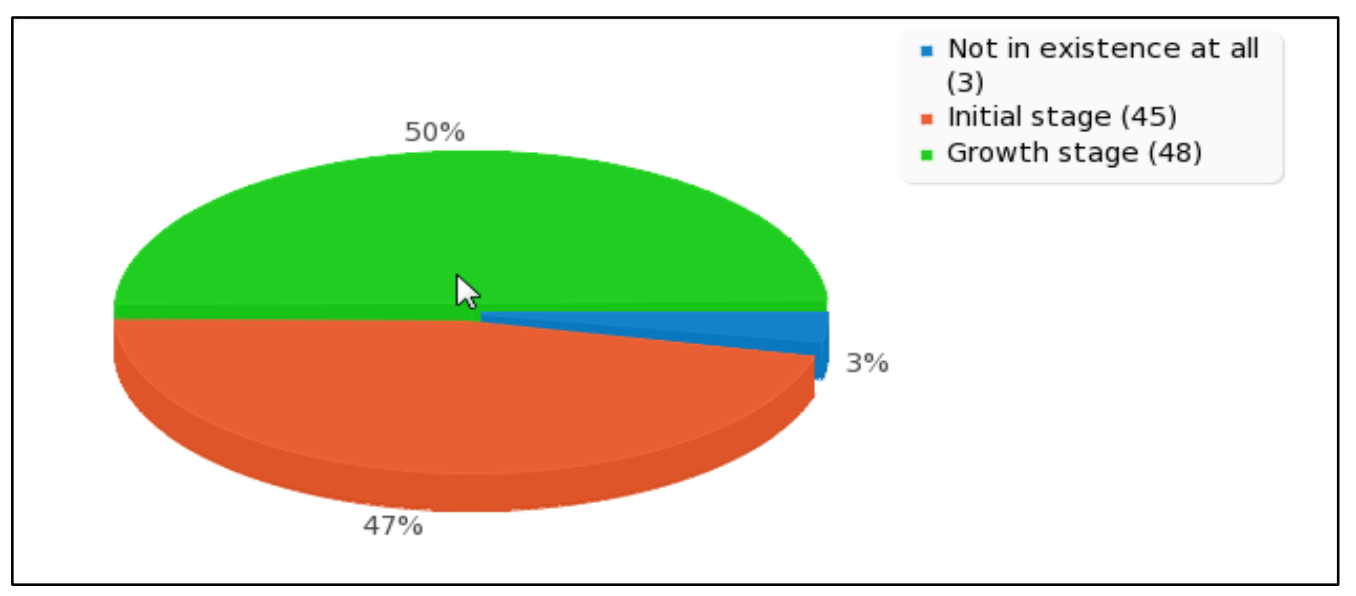

Figure 2. Perceived of Current Status of KM in the Organization X

Figure 2 indicates that the majority of staff agreed that the current status of knowledge management is at initial stage and growth stage. This is because knowledge management has emerged as one of organization X's important agenda. Since the changes in the global economy and competitiveness, and the world emphasis on knowledge management, knowledge management has been introduced under
Group Asset Management and IT Department. Although, the result also reported that there are 3 number respondents has not identified that the existence knowledge management to organization $\mathrm{X}$, we may presume that they are new workers or had not participated in any of the in-house training offered to staff members. 


\section{Discussion}

It was discovered that the staff in Organisation X were aware and understood the importance of having knowledge management in the company. The contexts in which the process and activities were related to knowledge management were also identified.

\section{Level of Understanding}

Based on the findings, it can be said that the level of understanding of knowledge management among the staff of Organisation $\mathrm{X}$ was highly positive. The findings indicated that the staff members were knowledgeable of knowledge management based on their own expertise and skills that they had acquired through experience or education.

It can be assumed that the staff members were already familiar with the term based on their experience in the organisation. Furthermore, they had been involved in numerous programs such as seminars, conferences, meetings, etc. In addition, most of the staff members were highly educated, indicating their understanding of the knowledge management field.

\section{Awareness of Knowledge Management}

Ninety-two percent of the respondents stated that they were aware of the term, 'knowledge management'. The respondents knew the term from the KM literature, learning from colleagues, practical work, and workshops, including professional and academic conferences. Additionally, 92\% of respondents indicated they had undertaken formal education and had obtained a Degree or a Master's Degree from a university.

\section{Benefits of Knowledge Management Implementation}

During the interview sessions, the KMS realised that knowledge management has a significant impact on the business performance of Organisation $X$. The respondents admitted that the benefits of
KM contributed to improving the organisation's operation and services.

\section{Problems Faced in Implementing KM}

During the implementation process, the respondents in Organisation $X$ claimed that they could not deny that several problems existed in their organisation. The interviews revealed several problems at the managerial stage. The problems are briefly described as follows:

a) The KM leaders keep changing

b) Unclear policy and direction towards KM

c) Lack of commitment towards the KM system

d) No formal training in KM

e) Lack of awareness, and no promotional activities were conducted

f) A low participation and contribution from staff, including a low appreciation of sharing culture

g) Lack of a knowledge contribution

h) An unfriendly user interface

i) Outdated technology

j) An inadequate population in the database of facilities to share knowledge

The respondents indicated that problems occurred due to a reluctance to share knowledge among staff. This scenario can be caused by security issues or the lack of a knowledge-sharing culture in Organisation $X$. Another finding showed that a lack of awareness regarding knowledge sharing existed. The findings also showed that staff did not know about the knowledge needs of other staff; therefore, they were unwilling to share their knowledge. 


\section{Recommendations}

Several recommendations from various successful organisations from more developed countries have been highlighted in this study. Among the recommendations that need to be considered before, during and after the implementation of KM are the following:

Bishop et al. (2008) has recommended that for an organisation to obtain benefits from the implementation of knowledge management, the organisation should

- Develop a clear definition of KM and a high level of understanding throughout the organisation.

- Ensure that the KM programme fits the needs of the staff and the organisation's objectives.

- Incorporate the KM programme into the organisation and the daily work of staff.

- Implement a KM initiative and a supporting team.

- Establish top management support for the implementation of knowledge management.

- Clearly demonstrate the benefits and initial successes of the KM initiative.

- Determine the appropriateness of rewards and recognition.

It was recommended that for an organisation to obtain benefits from the implementation of knowledge management, the organisation should consider the following components of KM implementation (Chong et al., 2000):

\section{- Knowledge Investment}

It is essential that top management should invest in a knowledge programme, and they should allocate a budget to support the programme.

\section{- Knowledge Team}

Staff should understand the importance and value of knowledge management. Knowledge cannot be managed properly until all staff members within the organisation have clear responsibilities for KM work.

\section{- Technology Infrastructure}

A technology infrastructure should be developed to support and deliver knowledge within the organisation.

\section{- Organisational}

The organisational performance can be influenced by strategic and operational objectives, staff and KM tools. An organisation should develop a corporate mission, policies and knowledge practices to be effective in the implementation of knowledge management.

Furthermore, Disterer, G (2002) highlighted several actions that need to be considered to foster knowledge sharing in organisations, such as the following:

\section{- Concern and Trust}

An attitude of concern and trust is a prerequisite for knowledge sharing among staff within organisations. An organisation should develop a common set of ethical standards and values to create knowledge management practices and habits. These standards and values should be stated clearly and communicated throughout the organisation.

\section{- Leadership}

Leadership plays an important role because of their responsibility to nurture, support and encourage staff to share knowledge. Therefore, management should create a knowledge-sharing programme where all the staff must openly share their experiences, knowledge, etc. 


\section{- Rewards and Incentives}

Methods involving rewards and incentives are required in organisations. These can act as an extrinsic motivation for staff to share knowledge. To be successful, an organisation needs to encourage their staff through personal recognition and reputation when their staff members have actively participated in knowledge sharing.

\section{- Tutoring and Mentoring}

Tutoring and mentoring can foster common habits and attitudes among staff members. It also can support communication among staff members in organisations.

\section{- Project Experiences}

Each department in an organisation should be willing to share their project experiences with other departments. The lessons learned could be systematically analysed and stored for access and use by other staff. Knowledge and experiences gained in projects can be used to assist in the development of other projects.

\section{- Communities of Practice}

Creating a community of practice is prominent approach to cultivate knowledge sharing within organisations. These groups of professionals enhance the ability of staff members to think, share ideas, and discuss the problem with each other. Therefore, knowledge sharing can be created through this approach.

More efforts and approaches are warranted to further develop knowledge management based on cultural and social norms and create awareness of the importance of knowledge management in organisations. Organisation X needs to develop a strategic plan to implement knowledge management, and management should maintain this to encourage the sharing of knowledge among staff.

Furthermore, there is a need to plan a comprehensive program for various groups of staff and to narrow the information and knowledge being transferred and shared among staff without introducing any cultural barriers. Effective knowledge and cultural audits are also vital to a successful knowledge management project. Choosing the right tools and frameworks is equally important to achieving the implementation of knowledge management in organisations.

Finally, Organisation X should focus on encouraging its staff to convert their tacit knowledge to explicit knowledge so that it can easily be shared among staff. Thus, the recommendations should be able to enhance the level of knowledge management implementation not only within Organisation $\mathrm{X}$ but also within other organisations.

\section{Conclusions}

Even in established organizations, there is a need to strengthen the implementation process to sustain knowledge management within the company. To enhance this, more effort and research are needed to support this determining factor and thereby facilitate the full preparation of an organization to implement knowledge management. Secondly, the results highlight the importance of leadership in this change processes. Leaders must be capable of communicating the need for change in a convincing manner and ensure that the transfer of knowledge management is successful at all level of staff. Lastly, tutoring, mentoring and rewards are required to enable the successfulness $\mathrm{KM}$ adoption in a company.

\section{Acknowledgements}

This project was funded by the University Technology MARA Research Intensive Excellence Fund 600-RMI/DANA 5/3/RIF (649/2012). We thank the participants and the top managements of the company for granting permission to conduct this study. 


\section{References}

Bishop, J., Bouchlaghem, D., Glass, J. \& Matsumoto, I. (2008). "Ensuring the Effectiveness of a Knowledge Management Initiative," Journal of Knowledge Management, 12, 16-29.

Chong, C. W., Holden, T., Wilhelmij, P. \& Schmidt, R. A. (2000). "Where Does Knowledge Management Add Value?," Journal of Intellectual Capital, 1, 366-380.

Chong, S. C. (2006). "KM Critical Success Factors: A Comparison of Perceived Importance versus Implementation in Malaysian ICT Companies," Learning Organization, The, 13, 230-256.

Chong, S. C., Yew, W. K. \& Lin, B. (2006). "Criteria for Measuring KM Performance Outcomes in Organisations," Industrial Management \& Data Systems, 106, 917-936.

Chowdhury, N. (2006). 'Building KM in Malaysia,' Inside Knowledge, 9.

Disterer, G. (2002). "Management of Project Knowledge and Experiences," Journal of Knowledge Management, 6, 512-520.

Greiner, M. E., Böhmann, T. \& Krcmar, H. (2007). "A Strategy for Knowledge Management," Journal of Knowledge Management, 11, 3-15.

Hoon, T. H., Ramayah, T. \& Jantan, M. (2003). "Knowledge Management: An Exploratory Study on Malaysian Organizations," The International Journal of Knowledge, Culture and Change Management.

Jayasingam, S., Ansari, M. A., Ramayah, T. \& Jantan, M. (2012). "Knowledge Management Practices and Performance: Are they Truly Linked \&Quest;†," Knowledge Management Research \& Practice.

Karadsheh, L., Mansour, E., Alhawari, S., Azar, G. \& EL-Bathy, N. (2009). 'A Theoretical Framework for Knowledge Management Process: Towards Improving
Knowledge Performance,' Journal of Communications of the IBIMA, 7.

Lang, J. C. (2001). "Managerial Concerns in Knowledge Management," Journal of Knowledge Management, 5, 43-59.

Lindsey, K. L. (2006). 'Knowledge Sharing Barriers,' Processes of Knowledge Management, 499-506.

Lucas, L. M. (2006). “Things are Not Always What they Seem: How Reputations, Culture, and Incentives Influence Knowledge Transfer," Learning Organization, The, 13, 7-24.

Marshall, C., Prusak, L. \& Shpilberg, D. (1996). "Financial Risk and the Need for Superior Knowledge Management," California Management Review, 38, 77-101.

Mccann, J. E. \& Buckner, M. (2004). "Strategically Integrating Knowledge Management Initiatives," Journal of Knowledge Management, 8, 47-63.

Mcdermott, R. \& O'dell, C. (2001). "Overcoming Cultural Barriers to Sharing Knowledge," Journal of Knowledge Management, 5, 76-85.

Mohammed, M. Y. B. (2007). 'Knowledge Content in Key Economic Sectors in Malaysia,' A Speech by the Minister in the Prime Minister's Department at the Launch of the 2004 Report on Knowledge Content in Key Economic Sectors in Malaysia.

Plessis, M. D. \& Boon, J. A. (2004). "Knowledge Management in eBusiness and Customer Relationship Management: South African Case Study Findings," International Journal of Information Management, 24, 7386.

Rahman, B. A. (2004). 'Knowledge Management Initiatives: Exploratory Study in Malaysia,' Journal of American Academy of Business, 4, 330. 
Rezgui, Y. (2007). "Knowledge Systems and Value Creation: An Action Research Investigation," Industrial Management \& Data Systems, 107, 166-182.

Salleh, A., Richardson, S. \& Narayanan, R. (2003). 'Knowledge Management: A Malaysian Study,' Malaysian Manage. Rev, 38, 79-89.

Sanchez, P., Chaminade, C. \& Olea, M. (2000). "Management of Intangibles-An Attempt to Build a Theory," Journal of Intellectual Capital, 1, 312-327.

Syed-Ikhsan, S. O. S. \& Rowland, F. (2004). "Benchmarking Knowledge Management in a Public Organisation in Malaysia," Benchmarking: An International Journal, 11, 238-266. 